Brazilian Journal

of Chemical

ISSN 0104-6632

Engineering

\title{
MULTI-OBJECTIVE OPTIMIZATION OF SUPERCRITICAL WATER GASIFICATION OF LEFTOVER BRAZILIAN GINSENG ROOTS AFTER PHYTOCHEMICAL RECOVERY STEPS
}

\author{
J. Q. Albarelli1 ${ }^{1}$ A. Mian' ${ }^{2}$ D. T. Santos ${ }^{1 *}$, A. V. Ensinas ${ }^{2}$, \\ F. Maréchal ${ }^{2}$ and M. A. A. Meireles ${ }^{1}$ \\ ${ }^{1}$ LASEFI/DEA/FEA, School of Food Engineering, University of Campinas. Cidade Universitária "Zeferino Vaz", \\ Rua Monteiro Lobato, 80, 13083-862, Campinas, SP, Brazil \\ *E-mail: diego_tresinari@yahoo.com.br; Phone: +55 193521 0100; Fax: +55 1935214027 \\ ${ }^{2}$ Industrial Process and Energy Systems Engineering (IPESE), École Polytechnique Fédérale de Lausanne (EPFL), \\ Station 9, 1015, Lausanne, Switzerland
}

(Submitted: April 30, 2015; Revised: April 29, 2016; Accepted: April 30, 2016)

\begin{abstract}
The present study aims at studying the supercritical water gasification (SCWG) of leftover Brazilian ginseng roots after phytochemicals extraction for synthetic natural gas (SNG) production, envisioning the development of a promising Brazilian ginseng roots valorization using sub/supercritical fluids in different steps. A multi-objective energetic-economic-environmental optimization of the proposed SCWG process was assessed through the use of computational simulation tools. The results showed that, for a given leftover biomass input of 20MW, a specific cost of 62-66 USD/MWh of SNG is obtained, which is higher than the average price on the Brazilian market. On the other hand, the production process of SNG from this residue showed to be a promising option, being energetically selfsufficient and environmentally friendly. In order for this alternative process to become more economically attractive we proposed the construction of the SCWG and the sub/supercritical extraction units in the same location, sharing part of the same high-pressure equipment.
\end{abstract}

Keywords: Hydrothermal Gasification, Pfaffia glomerata, Biorefinering, Biomass Valorization, Computational Simulation.

\section{INTRODUCTION}

During recent years, the interest on biomass utilization for power generation has increased since it has significant environmental benefits. It is an abundant resource that could provide renewable energy with low $\mathrm{SO}_{2}$ and $\mathrm{CO}_{2}$ emissions, contributing positively to limit the greenhouse effect. Gasification combined with a gas engine or gas turbine has the advantage of having a higher electric efficiency and lower electricity production costs than direct combustion (Bridgewater, 1995). In addition, different types of liquid fuels can be synthesized from the produced synthetic natural gas (SNG), such as Fischer-Tropsch crude fuel, dimethyl ether and methanol, to generate renewable fuels to substitute fossil fuels, especially in the transportation sector which is responsible for a large part of the global $\mathrm{CO}_{2}$ emissions.

\footnotetext{
* To whom correspondence should be addressed
} 
Different gasification technologies have been studied for biomass conversion, including the use of the supercritical water gasification $(\mathrm{SCWG})$ process. Sometimes referred to as hydrothermal gasification, SCWG benefits from the special properties of near-supercritical and supercritical water as solvent and reactant, respectively. This process is performed at conditions near or above the critical point of water: $647 \mathrm{~K}\left(374{ }^{\circ} \mathrm{C}\right)$ and $22.1 \mathrm{MPa}$. This technology achieves high conversions and avoids energyintensive biomass-drying processes, which are required in conventional gasification technologies, allowing its direct use for wet biomasses (Kruse, 2009; Zöhrer and Vogel, 2013).

This work is a part of a project that aims at providing routes to valorize the Brazilian ginseng plant. Recently, scientists have shown great interest in Brazilian ginseng (Pfaffia glomerata) roots, due to the pharmaceutical properties of the roots attributed to the $\beta$-ecdysone content demonstrating similar effects to Panax ginseng (Zimmer et al., 2006). In addition, other important compounds have been identified and could be also recovered with a subsequent extraction process. Our research group has demonstrated that pressurized ethanol, with or without the addition of $\mathrm{CO}_{2}$, can successfully be applied as solvent for extracting selectively $\beta$-ecdysone from $P$. glomerata roots (Leal et al., 2010; Santos et al., 2014). On the other hand, a recent patent developed by us described that water can be used as extracting solvent for obtaining a saponin-rich extract that can be used directly as surfactant (Meireles et al., 2013). So, a two-step process using pressurized ethanol with or without the addition of $\mathrm{CO}_{2}$ at sub/supercritical state in the first extraction step and subcritical water in the second seems very promising. Since the wet residue from this two-step extraction process normally constitutes a high proportion of the inlet ginseng, the valorization of this residue can be the key factor to increase economic attractiveness of the proposed extraction process. Since in supercritical water gasification (SCWG) biomass does not need to be dried, using this wet residue is one alternative route that should be analyzed.

Fuel production systems involve a large number and various types of interactions with the world outside their physical boundaries. The process designer must, therefore, face many issues, which deal primarily with the energetic, economic and environmental aspects of the system. In general, objectives involved in the design optimization process are: energetic (e.g., maximum energy efficiency, minimum fuel consumption, minimum irreversibility and so on), economic (e.g., minimum cost per unit of time, maximum profit per unit of production) and environmental (e.g., limited emissions, minimum environmental impact). The multi-objective optimization of a process represents a paradigmatic application of a single objective optimization, since it suffers from the difficulty to find a final global optimum. The mathematical approaches are generally unsuccessful in finding the global optimum and most of them terminate at local optima in the multi-modal optimization problem. In this context, the present study aims at evaluating the SCWG of leftover Brazilian ginseng roots after phytochemicals recovery for SNG production by computational simulation through the use of a multiobjective energetic-economic-environmental optimization for the SCWG process, envisioning the development of a novel Brazilian ginseng roots valorization using sub/ supercritical fluids during all the plant material processing.

\section{MATERIAL AND METHODS}

\section{Description of the proposed valorization route for Brazilian ginseng roots}

In the present study, the production of synthetic natural gas (SNG) from leftover Brazilian ginseng roots after phytochemical recovery through supercritical water gasification (SCWG) was evaluated. A simplified representation of the SCWG process is presented in Figure 1 . This process was experimentally validated using a demonstration plant (maximum flow rate of $1 \mathrm{~kg} / \mathrm{h}$ ), which was described by Waldner (2007) for the continuous SCWG of wet biomasses built at the Paul Scherrer Institute in Switzerland. The key independent variables of the process are related to the operating pressure, which was set at $30 \mathrm{MPa}$ for this study, and the maximum temperature to be achieved in the salt separation step, which highly affects the utility integration problem.

An inlet mass flow of 20MW presenting a solid concentration of $20 \%$ is used. The considered elementary composition of the residue in the analyses is shown in Table 1. The elementary composition was measured experimentally using a isoperibolic bomb calorimeter, analyzing the leftover Brazilian ginseng (Pfaffia glomerata) roots after two semi-continuous sequential phytochemical recovery processes, i.e., employing pressurized ethanol with addition of $\mathrm{CO}_{2}\left(10: 90 \%\right.$, w/w, ethanol: $\left.\mathrm{CO}_{2}\right)$ in the supercritical state ( $20 \mathrm{MPa}$ and $303 \mathrm{~K}$ ) in the first extraction step and distilled pressurized water in a subcritical state (12 $\mathrm{MPa}$ and $353 \mathrm{~K})$ in the second.

The first step in the SCWG process is the waste slurry compression to $30 \mathrm{MPa}$ and heating to near the critical conditions of 623-653 K. In this step, the hydrolysis of the organic matter occurs, and the salts in the waste slurry can be separated when the solution is heated above the pseudo-critical point (Gassner and Maréchal, 2009). To avoid incrustations and damage to the equipment, the salts are separated in a cyclone preview that enters the gasifier. The liquid hydrolysate is sent to a fixed bed of a nickelor ruthenium-based catalyst, which converts $99.9 \%$ of the organic matter into $\mathrm{CH}_{4}, \mathrm{CO}_{2}$ and $\mathrm{H}_{2}$ with traces of $\mathrm{CO}$. After the gasification, a product separation unit is considered to increase the $\mathrm{CH}_{4}$ concentration to achieve 


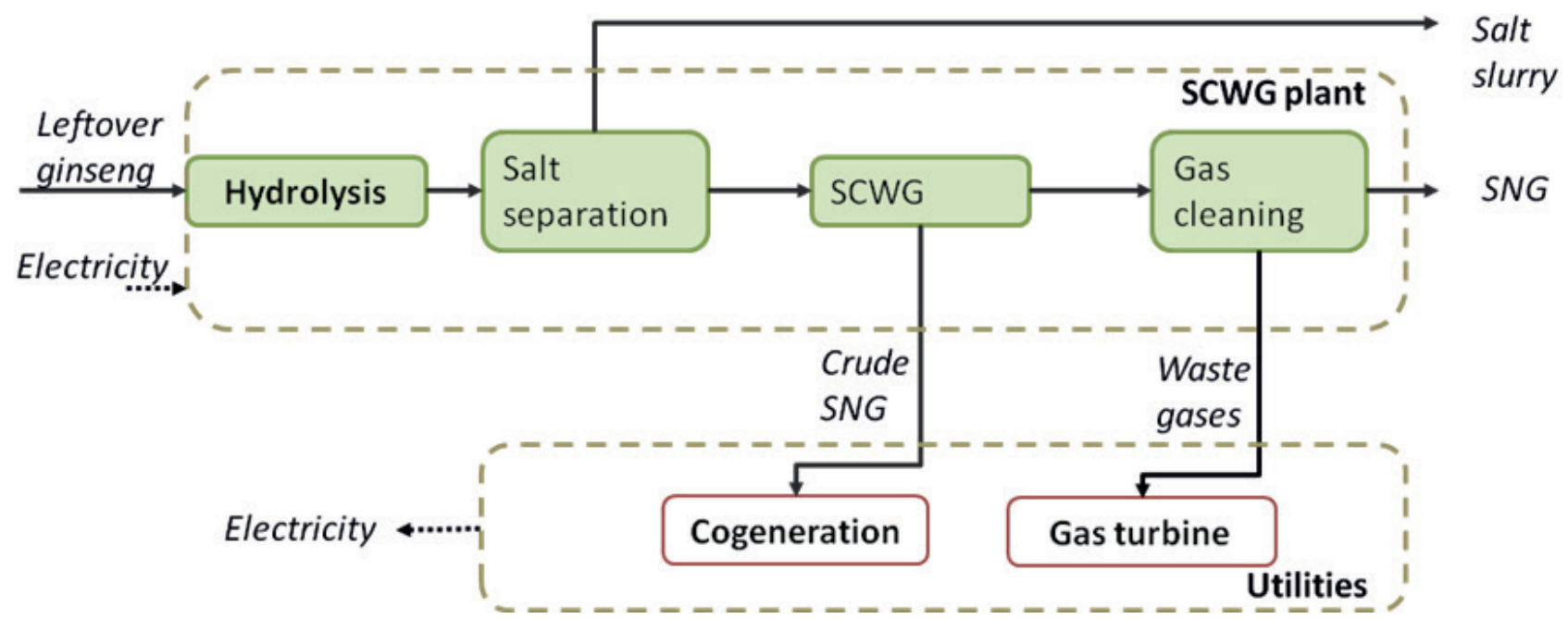

Figure 1. Block diagram of the supercritical water gasification (SCWG) process to produce synthetic natural gas (SNG) and electricity from the leftover ginseng

Table 1. Experimentally determined elementary composition of the leftover Brazilian ginseng (Pfaffia glomerata) roots after the considered two sequential phytochemical recovery processes (on a dry basis)

\begin{tabular}{cc}
\hline & Composition (\%) \\
\hline Carbon & 44.6 \\
Hydrogen & 6.2 \\
Oxygen & 48.0 \\
Nitrogen & 1.0 \\
Sulphur & 0.2 \\
\hline
\end{tabular}

the required purity of $96 \mathrm{~mol} \%$ by the natural gas grid. A high-pressure water absorption column coupled with a membrane is analyzed for the final $\mathrm{CO}_{2}$ removal. The final obtained product is grid quality SNG with methane content of $96 \% \mathrm{v} / \mathrm{v}$ and pressure of $7 \mathrm{MPa}$. A steam-based cycle cogeneration system was considered to supply heat and power to the process. Live steam at $793 \mathrm{~K}$ and $9 \mathrm{MPa}$ and condensing extraction steam turbines are simulated, and the entire system is integrated with the process design when the heat cascade problem is solved. For the cogeneration unit, the waste gases from the SCWG gas cleaning system were considered as fuel. When extra thermal energy was required, a post-oxidation steam-injected gas turbine that operated with crude SNG was considered (Figure 1).

Computational optimization methodology

The basic concept of the developed simulation model is the decomposition of the problem into several parts. First, the SCWG process described in the previous section is simulated in commercial flowsheet software: Belsim Vali (Belsim Vali, 2013). The model determines the species conversion and calculates the associated heat and power balances. A detailed description of the considered model was published by Gassner et al. (2011). Then, an energetic-economic-environmental model is constructed in the OSMOSE platform (OSMOSE, 2013). OSMOSE (OptimiSation Multi-Objectifs de Systemes Energetiques integres, which means "Multi-Objective OptimiZation of integrated Energy Systems") is a computational platform that was built in Matlab (Mathworks, 2013), developed and continuously improved at École Polytechnique Fédérale de Lausanne in Switzerland for the design and analysis of integrated energy systems. The platform allows one to link several commercial softwares such as Belsim Vali and Aspen Plus for a complete suite of computation and result analysis tools (optimization, sensitivity analysis, Pareto curve analysis, etc.).

The energetic-economic-environmental model is constructed as follows:

Energetic model: uses the heat and cooling streams simulated in the Belsim Vali model to enable heat integration of the thermal fluxes using the pinch analysis methodology (Linnhoff, 1982). The minimum energy requirement is computed from the hot and cold process streams using the heat cascade method, which accounts for the potential heat recovery. The potential fuels are assembled in a superstructure, which integrates different possibilities and computes the optimal solution by minimizing the operating cost using a linear programming model (Molyneaux et al., 2010). The optimal thermal process integration is computed in the OSMOSE platform after the maximum heat recovery potential between hot and cold streams is defined.

Economic model: uses the mass streams simulated in the Belsim Vali model and the solution found in the energetic model to size the major process equipment and calculate their purchase cost, which is adjusted to account for specific process pressures and materials using 
correlations from the literature (Turton, 2009; Ulrich and Vasudevan, 2003). The total investment cost is calculated using multiplication factors to consider indirect expenses such as labor, transportation, fees, contingencies and auxiliary facilities. The operating costs consider the cost of labor, maintenance ( $5 \%$ of the total investment), the main raw materials and electricity (when necessary). The production cost is the sum of the operating cost and the depreciation cost, which is the total investment cost annualized. The Marshall \& Swift coefficient (Marshall \& Swift Equipment Cost Index, 2013) was used to update the cost data to the year 2013 from the values in the reference literature. The main economic assumptions in the economic analysis are shown in Table 2.

Table 2. Economic assumption used in the analysis

\begin{tabular}{lcc}
\hline Data & Value & \\
\hline Economic data & & \\
Project lifetime & 25 & years \\
Construction and startup & 2 & years \\
Depreciation & 10 & years \\
Interest rate & 15 & \% year \\
Marshall and Swift index & 1530 & \\
Days worked in a year & 90 & \% days/year \\
\hline
\end{tabular}

Environmental model: uses the mass streams simulated in the Belsim Vali model and equipment sized in the economical model to calculate the environmental impact using the impact data developed by the IPCC (Intergovernmental Panel on Climate Change), which considers a time horizon of 100 years for the GWP (global warming potential). The environmental performance indicators in this methodology are calculated while solving the optimal design problem according to Gerber (Gerber, 2012). In this context, a LCA model is defined to consider the impact contributions from the involved material and the energy flows during the operation phases and environmental effects related to the construction, operation and end of life of the process equipment. For the LCA, the emission contribution for the IPCC07 (Intergovernmental Panel on Climate Change 07) impact assessment method was considered and reported in terms of GWP 100 as the environmental performance indicator (Ecoinvent centre, 2013).

The proposed SCWG process was evaluated by performing a multi-objective optimization using an evolutionary algorithm (Molyneaux et al., 2010; Gassner and Maréchal, 2009) using the OSMOSE platform.

The considered multi-objective optimization methodology, which was presented in detail by Gassner and Maréchal (2009), applies a two-step approach to overcome the complexity of the design problem, which falls in the category of Mixed-Integer Non-Linear Problems (MINLP). The optimization algorithm consists of a bi-level optimization. The so-called "master optimization" uses a genetic evolutionary algorithm to address variables that concern the unit size (real variables) and unit use (integer variables). The optimization sub-problem considers the linearized costs and is used to assure the maximum energy recovery potential and minimal environmental impact among process streams. The optimal process configurations that result from this methodology are available in the Pareto curve, which allows displaying the trade-off of the best solutions with respect to the considered objective functions. The set of points identifies the bounds of the feasibility region and the non-feasibility region (all the region where the value of the objectives are lower (in case of minimization) or higher (in case of maximization) than the Pareto points.

The objectives defined for the multi-objective analysis were: (i) SNG production; (ii) annual cost; (iii) environmental impact. The calculation of each objective is described in detail in the following section "Process performance indicators". The multi-objective optimization problem aimed at maximizing the SNG production, minimizing the annual costs and environmental impact. To reduce the computation time, which may limit the initial population and number of evaluations that must be performed by the optimizer, the number of variables must be accurately selected. The decision variables that are

Table 3. Assumed variables for the multi-objective optimization problem

\begin{tabular}{|c|c|c|c|}
\hline Process Unit & Parameter & Value & Units \\
\hline \multirow{4}{*}{ SCWG: salt separation unit } & Maximum temperature & {$\left[\begin{array}{ll}743 & 853\end{array}\right]$} & K \\
\hline & $\Delta \mathrm{T}_{\text {ss int }}$ & [20 40] & K \\
\hline & $\Delta \mathrm{T}_{\text {ss bottom }}$ & [20 40] & K \\
\hline & $\Delta \mathrm{T}_{\text {ss top }}$ & [20 40] & K \\
\hline \multirow{2}{*}{ SCWG: gasifier unit } & Gasifier pressure & {$\left[\begin{array}{ll}22 & 30\end{array}\right]$} & $\mathrm{MPa}$ \\
\hline & Gasification temperature & {$\left[\begin{array}{ll}623 & 673\end{array}\right]$} & K \\
\hline \multirow{2}{*}{ Heat recovery steam cycle } & Pressure level & [2 7] & $\mathrm{MPa}$ \\
\hline & Super-heating $\Delta \mathrm{T}$ & {$\left[\begin{array}{ll}30 & 80\end{array}\right]$} & K \\
\hline
\end{tabular}


considered in this study are reported in Table 3. An initial population of 100 cases was selected, and 2500 maximum evaluations were set as stopping criteria.

\section{Process performance indicators}

To estimate the conversion potential of different SCWG plant configurations three main performance indicators are defined:

(i) SNG production: was estimated by the model developed with the commercial flowsheet software: Belsim Vali (Belsim Vali, 2013)

(ii) Annual cost: was defined as the operational cost (Eq. 1) plus the annualized investment (Eq. 2), considering that the process operates $90 \%$ of the days/year.

$$
\begin{aligned}
& \text { Operational cost }=\text { cost labor }+ \text { cost maintenance }+ \text { cost raw material }+ \text { cost electricity } \\
& \text { Annualized investment }=\text { Total Investment } \operatorname{Cost} \times \frac{i \times(i+1)^{n}}{(i+1)^{n}-1}
\end{aligned}
$$

where $i$ is the annual interest rate and $n$ is the project lifetime in years.

(iii) Environmental impact: the environmental impact life cycle analysis (LCA) method was employed. The emission contribution for the IPCC07 impact assessment method was considered and reported in terms of GWP 100.

The economic performance of the proposed SCWG process was evaluated in terms of the total investment (Eq. 3 ) costs and break-even price of product (Eq. 5) that would make the technology profitable.

$$
\text { Total investment }=\left(\sum \text { equipment cost }\right) \cdot f_{m}
$$

where $f_{m}$ is the multiplication factor to consider indirect expenses such as labor, transportation, fees, contingencies and auxiliary facilities.

Production cost $=\frac{\text { Operational cos } t+\text { Annualized investment }}{\text { SNG production }}$

Break-even price $=$ selling price - production cost $=0$

The energy efficiency (Eq. 6) was also calculated to evaluate the process.

$$
\eta_{e}=\frac{\sum\left(L H V_{\text {products }} \times \dot{m}_{\text {products }}\right)+\dot{E}_{\text {produced }}}{\sum\left(L H V_{\text {inlet }} \times \dot{m}_{\text {inlet }}\right)+\dot{E}_{\text {consumed }}}
$$

where LHV is the low heating value of the flow, $\dot{m}$ is the mass flow, and $\dot{E}$ is the net electricity balance.

\section{RESULTS AND DISCUSSION}

The multi-objective optimization problem developed in this study aimed at finding the trade-off of the three selected conflicting objective functions, which minimizes the annual cost and environmental impact and maximizes the synthetic natural gas (SNG) production from leftover Brazilian ginseng roots by a supercritical water gasification (SCWG) process after phytochemical recovery via sub/ supercritical-based processes. The results of the multiobjective energetic-economic-environmental problem are depicted in Figure 2 in terms of the Pareto curve.

Each Pareto point represents an optimized configuration design for the SCWG process, which produces SNG. The decision variables that correspond to the optimized plant configurations of three selected Pareto points (Figure 2) are reported in Table 4. The more relevant energy flows and the related conversion efficiency are reported in Table 5 for three Pareto points.

The results of the optimization presented in the Pareto frontier (Figure 2) show that, for the same biomass input of $20 \mathrm{MW}$, the SNG production varies between 9.6 and 11.6 MW while the total yearly cost increases from 4.7 and 6.1 MUSD, which gives a specific cost of 62-66 USD/MWh of SNG. The curve trend shows that the increase in the efficiency reduces environmental impact due to the fact that the production of a renewable SNG is considered, replacing the same amount of fossil natural gas from the grid. The environmental impact is negative for all the optimum values presented in the Pareto curve and decreases even more with the increase of the efficiency, while requiring more investment.

As observed in Table 4, an increase in the gasifier pressure leads to higher biomass-to-biofuel conversion due to the reduction on the amount of crude SNG that must be burned to close the thermal energy balance of the plant. The increase in the SNG production by increasing the temperature in the salt separation unit and increasing the pressure in the gasifier results in an increase in the 


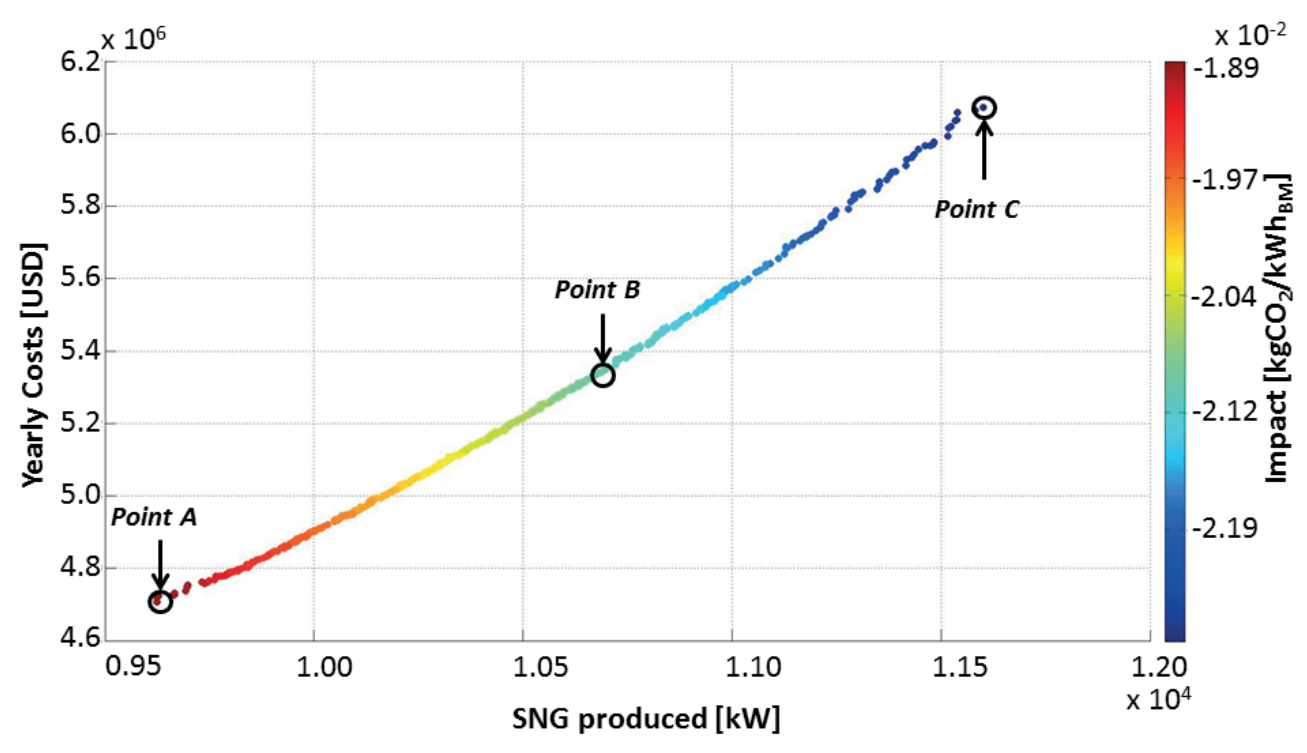

Legend: BM - input biomass

Figure 2. Results of the multi-objective energetic-economic-environmental optimization problem in terms of the Pareto curve

Table 4. Decision variables of three selected optimized supercritical water gasification plant configurations

\begin{tabular}{|c|c|c|c|c|}
\hline & Pareto Point A & Pareto Point B & Pareto Point $\mathrm{C}$ & Unit \\
\hline \multicolumn{5}{|l|}{ Results } \\
\hline Environmental impact & -0.0189 & -0.0205 & -0.0227 & $\mathrm{kgCO}_{2} / \mathrm{kWh}_{\mathrm{BM}}$ \\
\hline SNG produced & 9.62 & 10.42 & 11.60 & MW \\
\hline Annual cost & 4.71 & 5.16 & 6.07 & MUSD* \\
\hline \multicolumn{5}{|l|}{ Variables } \\
\hline Maximum temperature & 799.34 & 830.92 & 833.15 & K \\
\hline$\Delta \mathrm{T}_{\text {ss int }}$ & 37.90 & 33.86 & 35.80 & K \\
\hline$\Delta \mathrm{T}_{\text {ss bottom }}$ & 33.73 & 38.59 & 38.11 & K \\
\hline$\Delta \mathrm{T}_{\text {ss top }}$ & 34.42 & 34.69 & 33.77 & K \\
\hline Gasifier pressure & 22.00 & 24.72 & 30.00 & $\mathrm{MPa}$ \\
\hline Gasification temperature & 635.86 & 623.15 & 623.15 & K \\
\hline Pressure level & 4.67 & 4.82 & 4.73 & $\mathrm{MPa}$ \\
\hline Super-heating $\Delta \mathrm{T}$ & 62.32 & 79.60 & 53.07 & K \\
\hline
\end{tabular}

* Million US dollar

Table 5. Main results of three selected optimized supercritical water gasification plant configurations

\begin{tabular}{|c|c|c|c|c|}
\hline & Pareto Point A & Pareto Point B & Pareto Point C & Unit \\
\hline \multicolumn{5}{|l|}{ Power Input } \\
\hline Leftover ginseng input power & 20 & 20 & 20 & {$[\mathrm{MW}]$} \\
\hline \multicolumn{5}{|l|}{ Power Output } \\
\hline SNG output power & 9.6 & 10.4 & 11.6 & {$[\mathrm{MW}]$} \\
\hline \multicolumn{5}{|l|}{ Efficiencies } \\
\hline Energy efficiency & 48.1 & 52.1 & 58.0 & {$[\%]$} \\
\hline
\end{tabular}


annual cost of the SCWG process and a decrease in the environmental impact. The energy efficiency of the SCWG process increases $20 \%$ from Pareto Point A to C, representing a better use of the wet leftover ginseng to product, but at the expense of a $29 \%$ increase in the costs. The environmental impact also decreases 20\% from Point A to $\mathrm{C}$, representing a higher reduction when higher SNG is produced. The decision variables that most influence the present results are the maximum temperature in the salt separator and the temperature and pressure levels of the gasification reactor. The Pinch point of the evaluated process, i.e., the plant configuration when optimal thermal process integration is achieved, increases with the increase in the temperature of the salt separator and, as a consequence, the amount of heat required above the Pinch Point, which is provided by burning part of the crude product, is reduced. During the optimization the gasification temperature is driven to the lower bounds to allow maximizing the energy recovery between the salt separator output and gasification reactor input. The pressure level of the gasification step is increased, raising the power generation from vapor/liquid expanders that are placed in the separation phase. This affects the net electricity balance of the process and, as a consequence, impact contribution and profitability. In addition, high-pressure levels slightly reduce the thermal energy demand of the SCWG process.

The optimization of the steam cycle regarding the pressure levels and superheating temperature showed similar pressures, around $4.7 \mathrm{MPa}$, and superheating temperature for all Pareto points. It is important to highlight that, for all evaluated configurations, no external fuel was necessary to supply heat for the SCWG process, only lowquality product from the SNG production and a part of high-quality SNG (when necessary) were used to close the overall energy balance.

In the following sections, the energetic, economic and environmental performance indicators are presented to highlight the dependencies among these performance indicators and the comparison with literature data.

\section{Energetic evaluation}

Thermal process integration for each optimized point of Figure 2 was performed. Figure 3 presents the exergy composite curves of optimized Pareto point B of the SCWG process. No external fuel was necessary at any evaluated point. It can be observed that the proposed SCWG process from leftover ginseng presented good thermal process integration by observing the reduction of the area between the hot and cold streams in the Carnot factor-heat load diagram. This occurs because the difference in the thermal requirement temperature almost completely fulfills its energy demand by the cooling demand of the final step of the SCWG process. The energy demand of the SCWG process after thermal process integration is supplied by the cogeneration system using as fuel the waste gases, generated by the SNG cleaning system.

The set of utility streams that was activated during the optimization is included in the reported heat cascade curves (i.e., graphical representation of the overall heating and cooling demands in a process). Regarding the utility integration, it is interesting to show how the steam network was fitted in the heat cascade curve by optimizing the pressure level and steam superheating. The achieved results of this integration, which is calculated while optimizing the remaining hot and cold utilities, are reported in Figure 4. Steam superheating allows one to increase the mean thermodynamic temperature of the steam cycle, which increases the steam network efficiency. The Pinch Point activation is achieved in the obtained optimal solution.

Concerning the energy efficiency of this system (48.1$58.0 \%$ ), similar results were found when considering different biomasses in a SCWG process: algae $48 \%$ employing solar panel to electricity, (Mian et al., 2013a); algae 54\%; (Mian et al., 2013b); sugarcane bagasse 43-49 $\%$ (Mian et al., 2014).

In the work of Mian et al. (2013a), considering also a $20 \mathrm{MW}$ biomass input at the gasification step, the use of a solar system could increase the SNG production from $12 \mathrm{MW}$ of SNG to $14 \mathrm{MW}$ of SNG. This configuration could also be analyzed considering the current proposed valorization route for Brazilian ginseng wet residue in order to diminish the crude product burning, but as already presented by Mian et al. (2013a) this technology would imply a much higher cost for the investment. Therefore, in the present analysis this option was not taken into consideration.

\section{Economic evaluation}

The economic evaluation is a challenging part of this study mainly because of the difficulties in estimating the costs of the SCWG plant at large scale. The literature nonlinear cost function, which was considered to define the capital expenses for the global plant, led to the Pareto curve depicted in Figure 2.

Production cost was calculated for the present study as 62-66 USD/MWh of SNG. This today represents a cost 2.1 to 2.2 times higher than the actual cost for natural gas in the Brazilian market (30 USD/MWh of SNG). Table 6 shows the breakeven price for SNG using different wet biomass sources. A reduction in breakeven price for $\mathrm{SNG}$ is possible when considering the SNG production inside a biorefinery site, as evaluated by Albarelli et al. (2015). In that extent, the integration of the SNG production with the previous phytochemical recovery processes could be a possible way to decrease production costs of SNG. This could be easily achieved since part of the available infrastructure used for sub/supercritical extraction processes could be shared, for example expensive high-pressure pumps and vessels. A promising option could be the integration of the proposed 




Figure 3. Exergy composite curves of optimized Pareto point B of the SCWG process

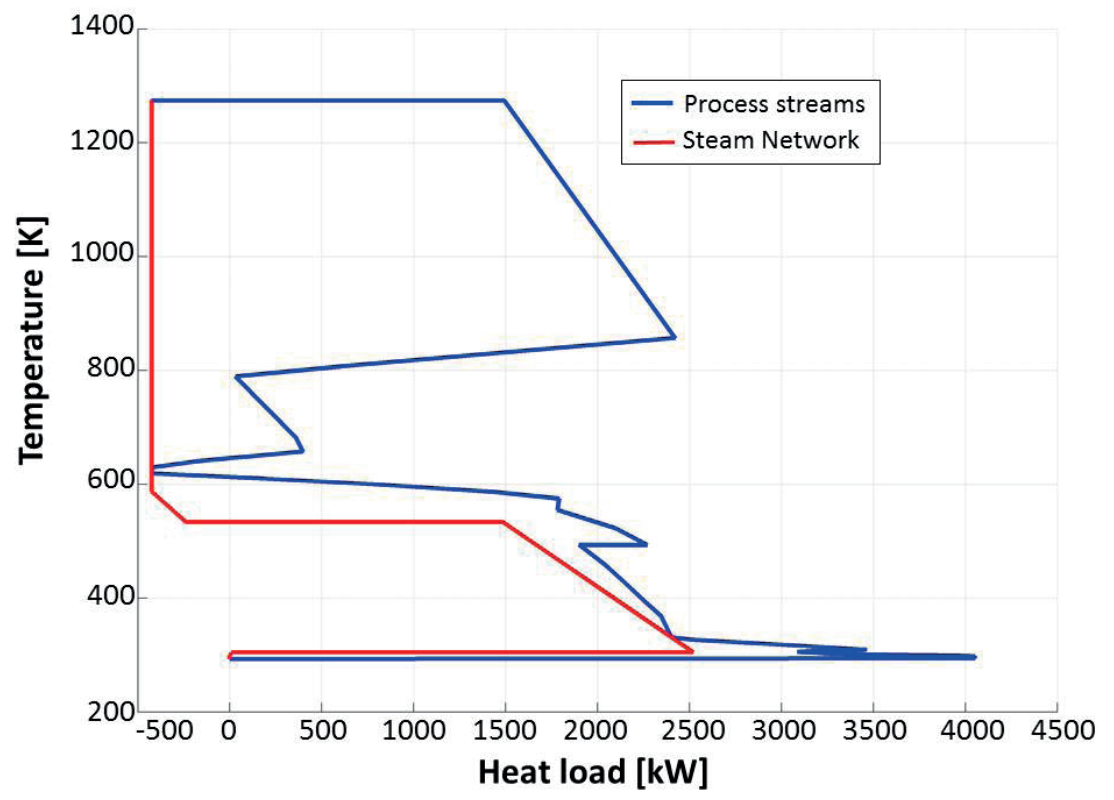

Figure 4. Integration of the steam network with the supercritical water gasification process

Table 6. Breakeven price for synthetic natural gas (SNG) production through supercritical water gasification process using different wet biomass sources

\begin{tabular}{lcl}
\hline \multicolumn{1}{c}{ Biomass source } & $\begin{array}{c}\text { SNG breakeven price } \\
\text { (USD/MWh) }\end{array}$ & \multicolumn{1}{c}{ Reference } \\
\hline Algae & $41-47$ & Mian et al. (2013b) \\
Sugarcane bagasse & $56-82$ & Mian et al. (2014) \\
Sugarcane bagasse & $0-27$ & Albarelli et al. (2015) \\
\hline
\end{tabular}


production process of SNG from the leftover ginseng co-located with the sequential sub/supercritical-based extraction process unit inside a sugarcane biorefinery producing ethanol, $\mathrm{CO}_{2}$, heat and electricity, which could be directly used in these specific processes, avoiding the need to buy these materials from outside. Besides, this final approach would result in mutual benefits for each production plant.

In addition, environmental benefits of the substitution of fossil fuels should also be taken into account in a decision-making process for implementing this alternative SNG production technology. A subsidiary benefit of this process is the separation of the salts that can be further recycled as fertilizer for the growth of Brazilian ginseng roots.

\section{Environmental effects}

For the life cycle analysis (LCA), the emission contribution for the IPCC07 (Intergovernmental Panel on Climate Change 07) impact assessment method was considered and reported in terms of GWP 100 (global warming potential considering a time horizon of 100 years) as the environmental performance indicator. The impact is analyzed for the global warming potential of the leftover ginseng conversion into SNG, including materials for construction of the process equipment. It must be highlighted that the impact of the process equipment is not so relevant in the final results, the operation of the system being responsible for the real gain in the GWP reduction. It was considered that the biomass is produced locally; therefore, the impact of the feedstock logistics of a big plant is not an issue. The impact reduction increased with the increase in the SNG production. Impact reduction in the same range was found when wet algae was used as an input biomass (Mian et al., 2013b) on a same scale as the SCWG plant.

\section{CONCLUSIONS}

The multi-objective optimization procedure was useful to identify the Pareto curve for an optimized supercritical water gasification (SCWG) process for production of synthetic natural gas (SNG) from wet leftover Brazilian ginseng roots after a two-step phytochemicals recovery process, accounting for the three objective functions: energy-economic-environmental. To that extent, it was possible to identify the main decision variables affecting the set of optimal solutions and their influence on costs, emissions and energy performances. The SCWG of wet leftover ginseng showed to be a promising technology with energy efficiency above $50 \%$ for the biomass conversion into biofuels, which is higher than most of the biomass conversion processes. Besides that, the possibility of fossil fuel substitution makes this conversion process very attractive from the environmental point of view. The production cost can represent a barrier to the feasibility of this proposed route, but probably by analyzing the overall proposed Brazilian ginseng valorization route, including the two-step extraction process also using sub/supercritical fluids, the attractiveness of this final step could increase.

\section{ACKNOWLEDGMENTS}

Juliana Q. Albarelli thanks FAPESP (processes 2013/18114-2 and 15/06954-1) for the post-doctoral fellowships. Diego T. Santos thanks FAPESP (processes 2010/16485-5 and 2012/19304-7) and CAPES for the post-doctoral fellowships. M. Angela A. Meireles thanks CNPq for the productivity grant (301301/2010-7). The authors acknowledge the financial support from CNPq and FAPESP (Processes 2009/17234-9; 2012/10685-8).

\section{NOMENCLATURE}

SCWG - SuperCritical Water Gasification

SNG - Synthetic Natural Gas

OSMOSE - OptimiSation Multi-Objectifs de Systemes

Energetiques integers

LCA - Life Cycle Analysis

IPCC07 - Intergovernmental Panel on Climate Change 07 GWP 100 - Global Warming Potential considering a time horizon of 100 years

\section{REFERENCES}

Ahmad S., Linnhoff B. and Smith R. Cost optimum heat exchanger networks-2. Targets and design for detailed capital cost models. Computers and Chemical Engineering, 14, 757767 (1990).

Albarelli J.Q., Mian A., Santos D.T., Ensinas A.V., Maréchal F. and Meireles M.A.A. Valorization of sugarcane biorefinery residues using supercritical water gasification: case study and perspectives. Journal of Supercritical Fluids, 96, 133-143 (2015).

Belsim Vali. v. 4.7.0.0. Available from: www.belsim.com (2013).

Bolliger R. Méthodologie de la synthèse des systèmes énergétiques industriels. Ph.D. Thesis. École Polytechnique Fédérale de Lausanne (2010).

Bridgewater A.V. The technical and economic feasibility of biomass gasification for power generation. Fuel, 74, 631-653 (1995).

Ecoinvent centre. Implementation of Life Cycle Impact Assessment Methods. Ecoinventreport. St. Gallen, July 2010. Available from: http://www.ecoinvent.org/fileadmin/ documents/en/03_LCIA-Implementation-v2.2.pdf (2013).

Gassner M. and Maréchal F. Methodology for the optimal thermo-economic, multi-objective design of thermochemical fuel production from biomass. Computers \& Chemical Engineering, 33, 769-781, (2009). 
Gassner M., Vogel F., Heyen G. and Maréchal F. Optimal process design for the polygeneration of SNG, power and heat by hydrothermal gasification of waste biomass: Thermoeconomic process modelling and integration, Energy \& Environmental Science, 4, 1726-1741, (2011).

Gerber L. Integration of Life Cycle Assessment in the conceptual design of renewable energy conversion systems, Ph.D. Thesis. École Polytechnique Fédérale de Lausanne (2012).

Kruse A. Hydrothermal biomass gasification. Journal of Supercritical Fluids, 47, 391-399 (2009).

Leal P.F., Kfouri M.B., Alexandre F.C.,. Fagundes F.H.R, Prado J.M., Toyama M.H. and Meireles M.A.A. Brazilian ginseng extraction via LPSE and SFE: global yields, extraction kinetics, chemical composition and antioxidant activity. Journal of Supercritical Fluids, 54, 38-45 (2010).

Linnhoff B. User Guide on Process Integration for the Efficient Use of Energy, 1st ed. Rugby: IChemE, 1982.

Mathworks. v. R2012b. Available from: http://www.mathworks. com/products/matlab (2013).

Meireles M.A.A., Vardanega R. and Santos D.T. Processo de Obtenção de um Extrato a Partir de Pfaffia glomerata. Brazil. Patent number: BR1020130128961 (2013).

Mian A., Albarelli J.Q., Ensinas, AV. and Maréchal F. Integration of Supercritical Water Gasification in Combined $1 \mathrm{G} / 2 \mathrm{G}$ Ethanol Production. Chemical Engineering Transactions, 39, 1795-1800 (2014).

Mian A., Ambrosetti G., Ensinas, AV. and Maréchal F. Optimal design of solar assisted hydrothermal gasification for microalgae to synthetic natural gas conversion. Chemical Engineering Transactions, v. 35, p.1009-1014 (2013a).
Mian A., Ensinas, AV. and Maréchal F. Multi-objective optimization of SNG production through hydrothermal gasification from microalgae. Computer Aided Chemical Engineering, 32, 337-342 (2013b).

Molyneaux A., Leyland G. and Favrat D. Environomic multiobjective optimisation of a district heating network considering centralized and decentralized heat pumps. Energy, 35, 751-758 (2010).

OSMOSE Platform: A tool for the design and analysis of integrated energy systems. 01 June 2013. Available from: http://leni.epfl.ch/osmose

Santos, D.T., Albarelli J.Q., Rostagno M.A., Ensinas, AV., Maréchal F. and Meireles M.A.A. New proposal for production of bioactive compounds by supercritical technology integrated to a sugarcane biorefinery. Clean Technology and Environmental Policy, 16, 1455-1468 (2014).

Turton, R. Analysis, synthesis, and design of chemical processes (3rd ed.) Prentice Hall, Upper Saddle River, 2009.

Ulrich, G. A guide to chemical engineering process design and economics a practical guide (2nd ed.), CRC, Boca Raton, 2003.

Waldner M.H. Catalytic hydrothermal gasification of biomass for the production of synthetic natural gas. . Ph.D. Thesis. Eidgenössische Technische Hochschule Zürich (2007).

Zimmer A.R., Bruxel F., Bassani V.L. and Gosmann G. HPLC method for the determination of ecdysterone in extractive solution from Pfaffia glomerata. Journal of Pharmaceutical and Biomedical Analysis, 40, 450-453 (2006).

Zöhrer H. and Vogel F. Hydrothermal catalytic gasification of fermentation residues from a biogas plant. Biomass and Bioenergy, 53, 138-148 (2013). 